\title{
Bilateral Trade and Islamic Sects
}

Rock-Antoine Mehanna, (E-mail: R.mehanna@wartburg.edu), Wartburg College

Leila Sarieddine, (E-mail: Lsarieddine@ home.com), Southern University

James L. Llorens, (E-mail: Jllorens@yahoo.com), Southern university

\begin{abstract}
This paper explores the effects of religion and Islamic sects on bilateral trade activities by employing an extended version of the gravity model. A stratified sample of 33 countries for the average period 1996-99 is selected. Although gravity models have been extensively used in the literature, to the best of our knowledge, they have neither been used to examine the impact of Islamic sects on bilateral trade nor to estimate religion within a model that incorporates oil-exporting countries, culture, regional trading arrangements, and political freedom-essential control variables for the specification of the model. Findings reveal that Muslim majority countries trade less than their Christian, Jewish, Buddhist, or other counterparts. In addition, when disaggregating the Muslim sample into Sunni and Shi'a sects, results show that Sunni majority countries trade more than their Shiite counterparts. Other results and policy implications are discussed.
\end{abstract}

\section{Introduction}

This paper examines the effects of religion as well as Islamic sects on bilateral trade activities across countries during the period of 1996-1999 by employing an extended version of the gravity model. Although gravity models have been extensively used in the literature to estimate bilateral trade, they have, to the best of our knowledge, never been used to assess the impact of Islam and Islamic sects on trade, while controlling for oil-exporting countries, culture (represented by language affiliation or colonial ties), regional trading arrangements, and political freedom - variables that could be relevant for the study of Islamic Trade.

Religion has been always an integral part of societies and countries. Regardless of the level of development of countries, religion may still play a critical role in affecting political parties, interest groups (e.g. labor unions, manufacturers, etc.), consumer preferences, consumption behaviors, and so forth. In other words, religion can influence directly or indirectly exports, imports, as well as trade policies and debates. This influence could range from protectionist to freer policies (tariffs, quotas, etc.), government subsidies, taxation, price control, antidumping regulations, and so on. In fact, a myriad of economic layers could be affected by religion, and trade could be one of them.

In today's world, ethnicity is an increasing part of many societies. Globalization made the movement of people much easier, and so their exposure to different sociocultural and religious experiences. In fact, the diversity and exposure of religious sects whether in Christianity, Islam, Judaism, or other religions have been on the rise. For instance, Islamic sects encompass Sunni, Shiite, Alawite, Druze, etc. while Christianity includes several sects such as Catholic, Protestants, Orthodox, and so forth.

Interestingly, the above mentioned influence of religion on different aspects of socioeconomic life extends further to the narrower sectarian category. Subsequently, the purpose of this study is to estimate empirically the impact of religion (specifically Islam) and hence of Islamic sects on trade to find out their significance. It is argued in this study that several religious (and sectarian) beliefs, preferences, attitudes, cultures, ideologies, laws, norms, and so on could either encourage or hinder trade. Therefore, it is hypothesized that countries with Muslim majority population tend to trade less than their Christian or other counterparts. In addition, Muslim Sunni are expected to trade more than their Shiite counterparts due to the closer interrelationship between religion (church) and state, and

Readers with comments or questions are encouraged to contact the authors via email. 
the greater influence of the Shari'a (Islamic law) on people's behaviors and national trade policies among Shiite majority countries.

Several trade impediments could be the result of an expected low intra-trade among Islamic and Shiite majority countries. These trade impediments are described as follows: inadequate infrastructure; lack of product complementarity; many protectionist policies (high tariffs, quotas, and voluntary export restraint); rugged terrain (diffi cult transportation in the Middle East, Afghanistan, etc.); income disparities; many inefficient state enterprises; and too much reliance on oil (unstable source of revenue, which is subject to volatile international prices). Furthermore, large bureaucratic governments, chronic budget deficits, legal barriers on foreign ownership, political and economic instabilities, insufficient political freedom and intellectual property rights (IPR), among other factors contribute to a non-conducive environment for trade.

This paper is organized as follows. Following this section, section II discusses Islam and Islamic sects. Section III presents a review of the literature. Section IV discusses the methodological design and specification of the gravity model. Section V analyzes the empirical results. And finally, section VI concludes the study and offers some policy implications.

\section{Islam and Islamic Sects}

Sunni and Shi'a are the two main branches of Islam. Although Sunni constitute the majority ( 85 percent) of the Muslim population in the world, Muslim Shiite are concentrated in some countries such as Iran (the most dominant Shiite country, 89 percent Shiite and 10 percent Sunni), Bahrain, Iraq, and Lebanon (majority Shiitealthough their governments are not) among other countries. For instance, Lebanon (30 percent Christians and 70 percent Muslims with a Shiite majority) has a Christian President, Sunni Prime Minister, and a Shiite Speaker of the House. Similarly, despite Iraq's and Bahrain's Shiite majority (Iraq: 65 percent Shi'a and 32 percent Sunni, while Bahrain: 70 percent Shi'a and 30 percent Sunni), both countries have a majority Sunni government. In the context of this study, however, Muslim as well as Sunni or Shiite countries are described based on the majority of the population and not the government.

It is essential to differentiate between the following terms "Arab", "Muslim", and "Middle Eastern". The term "Arab" describes an ethnic or cultural identity with Arabic its language (e.g., Syria, Egypt, etc.), while "Muslim" describes the religious affiliation of many people living in different countries such as Afghanistan, Kuwait, Indonesia, Brunei, and Malaysia. For instance, in the United States, Islam is among the fastest growing religions. America has 1200 mosques and Islamic centers, and 6 million adherents, while Muslim around the world count for more than 1.2 billion. The term "Middle Eastern" describes the geographic location of the country or citizen (e.g., Turkey, Cyprus, Lebanon, Israel, etc.) Of course, a country could be a combination of Arab, Muslim, and/or Middle Eastern.

The split between Sunni and Shiite dates back soon after the death of Prophet Mohammed — peace be upon him (in $632 \mathrm{CE}$ - Sana Hijriyah or Islamic year). Lying in his bed in the last moments of his life, Prophet Mohammed indicated "unclearly" his successor by naming "the closest to him". Subsequently, some interpret it as naming, his closest companion, Abu Bakr, who was sitting the closest to his bed; while others interpret it as naming his son-in-law Ali, the closest relative to him. Accordingly, the split occurred with the Sunni following Abu Bakr, and the Shiite following Imam Ali as their leader. However, the split remained mostly for political reasons.

Since Prophet Mohammed Muslim were mostly Arabs originating from the Arab Peninsula, having Damascus and Baghdad their main center cities for trade. Muslims were invaded by Western Crusaders, who built their own well-fortified castles in countries such as Syria as a sign of their strong existence. This occupation lasted until Salahuddine Al Ayyoubi liberated the Muslim Empire from the Crusaders. Muslims excelled in trade especially in textiles, art, and spices. Later, the Moguls came from the East and invaded again the Muslim Empire; however, ironically, those Moguls eventually converted to Islam and rebuilt the Muslim empire and made it flourish again. Subsequently, the Muslim Turks invaded the Moguls and established the Ottoman Empire with Istanbul its capital and Sultan Suleiman (a Sunni) its ultimate ruler. And farther to the East were the Persians of Iran (Shiite) who 
emerged as a main opponent to the Ottoman Empire and the Sunni expansion.

\section{Literature Review}

Several previous studies examined the effects of religion or culture on trade, however, to the best of my knowledge, none of those studies estimate the sectarian impact, especially in Islam. Other studies even treat religion interchangeably with language as a proxy for culture. For instance, Beckerman (1956) and Srivastava and Green (1986) examine the effect of cultural similarities by combining language and religion into one variable, and find it significantly linked to trade. Srivastava and Green (1986) acknowledge the limitation of the combined measure of cultural similarities, which does not consider the fact that nations could have several major religions (e.g. the United States or languages (e.g. Belgium).

In fact, culture and language are not the same, and therefore can not be combined to represent a single proxy. Culture usually includes shared values, beliefs, customs, and rituals, while language is the set of common sounds and symbols by which individuals communicate (Lazear, 1999).

Trade in Islam is based on the value patterns deeply ingrained in the Islamic faith. The Islamic guidelines of conducting trade activities are also affected by the limitation that the religion would impose on certain forms of trade and credit, which could considerably influence trade policies and consumer consumption behavior. Ghazali (1994) details comprehensive discussions on these forms of trade and credit that are regarded as usurious in nature and hence are prohibited. Several other studies investigate the role of Islam in monetary market behaviors (Choudhury, 1997).

Ensminger (1997) studies the transaction costs and Islam in Africa, and by using the transaction costs argument, he postulates that the association between the expansion of trade and conversion to Islam has been noted all over the world. Moreover, Valibeigi (1993) examines the formation of economic policy in post-revolutionary Iran. He finds out that after the Iranian revolution in February 1979, the theocratic Islamic state launches a comprehensive program known as "Islamization", which helps to lay the foundation of an Islamic system in Iran. This emerging economic role of an Islamic (majority Shi'a) state is mostly notable in the areas of land reform and foreign trade. He argues that some of these economic facets closely resemble those of the centrally planned socialist economies.

Nowadays, the Organization of Islamic Countries (OIC) is a diversified group in terms of their socioeconomic structures, economic and political systems and levels of development and resource endowments, in spite of the fact that it is the driving force of Islam that bring those countries together under the OIC umbrella. The OIC group comprises 57 member countries and commands around 20 percent of the world's population, 50 percent of the world's oil, and 40 percent of the world's export of raw materials.

Hassan (2000) reports that intra-OIC trade is significantly lower than his gravity equation predicted. However, the oil factor, a main bias element in many Islamic countries, is not adequately isolated. Other studies (AlAtrash and Yousef, 2000) estimate intra-Arab trade and find it to be also significantly low.

Cindoruk (1992) declares that the Islamic Common Market (ICM) is the long-term ideal for the Islamic countries. He argues that the political will of the leaders of the Islamic countries is the master key for the comprehensive solution of the ICM in order to overcome such difficulties as the outdated communication and transport systems inherited by the Islamic countries from their former colonial masters.

Samuel Huntington (1993) contends that civilization identity will be increasingly important in the future, and one consequence is that economic regionalism is increasing along civilization lines. He cites examples of the European Community (sharing Western Christianity and European Culture) and the rapid expansion of the Chinese/Confucian oriented culture countries (e.g., China, Singapore, Taiwan, Hong Kong, and the overseas Chinese communities in other Asian countries). He also cites another example of the Economic Cooperation Organization, consisting of 10 non-Arab Muslim countries, based on their common culture and religion, namely, Iran, Pakistan, Turkey, Azerbaijan, Kazakhstan, Kyrgystan, Tajikistan, Uzbekistan and Afghanistan. 
Despite past studies that examined the effects of religion, Islam, and culture on trade, still the Muslim sectarian impact has not yet been empirically explored. This research paper attempts to address this issue using a crosscountry study.

\section{The Model}

The gravity model offers a systematic framework for measuring the normal pattern of trade. International trade flows are determined by comparative advantage, possibility of intra-industry trade, transport cost, and so forth. Trade policy may revise the normal trade flows. A gravity model of international trade estimates the trade flow as a function of variables that directly or indirectly affects the determinants of normal trade flow. We can use a modified version of the gravity model to examine whether religion and religious sects hinder trade and imports in both reporter and partner countries or not, while controlling for additional pertinent variables such as regional trade arrangements and oil-exporting countries.

The gravity model has long been used for empirical studies of the pattern of trade (exports or imports). Specifically, the volume of trade or imports between two countries should increase with their real gross domestic products (GDP) - the so-called gravity variable, since large countries should trade more than small ones, and with per capita incomes, since rich countries should trade more than poor ones. It should diminish with geographical distance because proximity reduces transportation and information costs. Since the dependent variables in the gravity model are bilateral trade and imports between pairs of countries, each variable (other than distance) is entered in product form.

Researchers then add dummy variables for participation in various regional trade blocs. If one finds a positive coefficient on the dummy variable indicating that two countries, both of which participate in the same trade bloc, trade more with one another than predicted by their incomes and distance, then the conclusion drawn is that the bloc is trade creating for its members. If there is a negative coefficient on the dummy variable indicating that only one member of the pair participates in a particular trade bloc, this is taken as evidence of trade diversion vis-a-vis the rest of the world.

This empirical paper adopts an extended version of the gravity model to investigate the effects of Islam and Islamic sects (mainly between Sunni and Shi'a) on bilateral trade flows across countries for the average period 1996-99, while accounting for oil-exporting countries, language affiliation (a proxy for one aspect of culture), regional trading arrangements, and political freedom (a proxy for democracy). All these control variables seem germane and relevant for the study of Islamic trade. This is also substantiated by the appropriate specification of the model, which is supported by the specification test of the error term and the multicollinearity test $(\mathrm{R}<.6)$ - which detects any high multicollinearity between independent variables.

Rather than being limited to a specific categorized sample such as the OIC, where selection bias could cause econometric problems, this paper employs a global framework encompassing a stratified sample of 33 countries. Subsequently, the stratified sample (based on data availability) includes 17 Muslim countries from both Sunni (e.g., Saudi Arabia, Pakistan, Kuwait, etc.) and Shi'a (e.g., Iran, Bahrain, etc.), while the remaining 16 non-Muslim countries are selected from a stratified pool of Christians, Buddhists, Hindus, etc. ${ }^{1}$

The contribution of this paper lies in the inclusion of the religious (Islam) and sub-Islamic (Sunni) variables, while controlling for pertinent variables such as culture (language affiliation), oil-exporting countries, regional trading arrangements, and political freedom. It is argued that these variables could be germane and symbiotic to the examination of Islam [see Mehanna and Hassan, forthcoming].

The typical gravity model specification predicts that bilateral trade between two trading partners is a function of the size of their economies, populations (or per capita incomes), and the distance between them (Bergstrand, 1985):

\footnotetext{
${ }^{1}$ Muslim Countries: Saudi Arabia, Syria, Jordan, Egypt, Lebanon, Iran, Pakistan, Indonesia, Brunei, Somalia, Sudan, Bahrain, Uzbekistan, Afghanistan, Bangladesh, Turkey, Tajikistan. Non-Muslim Countries: France, Russia, United States, Israel, India, South Africa, Nigeria, Philippines, Bulgaria, India, Thailand, Venezuela, Brazil, Slovenia, Ukraine, Costa Rica.
} 
$T i j=f(G D P i, G D P j, P C I i, P C I j, D I S T i j)$,

where $T$ is the value of trade (exports, imports, or both) between countries $i$ and $j, G D P$ is the real gross domestic product (or GNP, the gross national product) is the so-called gravity variable and a proxy for the size of economy, $P C I$ is per capita income measured by GDP (or GNP) over population, and DIST is the geographic distance between the two countries' capitals. All these variables are logged.

Due to the specific nature of many Islamic countries as oil-exporters, methodological bias (oil bias) could be a result of inflating trade figures relative to non oil-exporting countries, thus overestimating Islamic trade activities. Therefore, we extend the standard model as follows. The dependent variable trade is presented in two forms: "total trade" (summation of imports and exports) and "imports". It is noticed here that "exports" are not included in this model to avoid the rising awareness of inflating the estimated coefficients, an issue addressed in recent studies as related to its improper econometric specification in gravity equations (Matyas, 1997). Imports' figures shield the variable from oil exports, whereas total trade values would be subject to imbedded oil exports. However, when using trade values as dependent variables, two dummy variables representing oil-exporters in reporting (country i) and partner (country j) countries are added to the equation to isolate the oil bias.

Moreover, the distances between countries' capitals could be also upwardly biased, hence exaggerating the distance of large size countries. Therefore, a dummy variable "border" is added to the model describing if the trading partners have common national borders. This "border" dummy variable is included to reduce the bias that the "distance" variable could carry from measuring distances between large size countries, a very plausible case in the Middle East, part of East Asia and central Europe regions. Following Mehanna's and Hassan's (2002) approach, "culture" is represented by two different variables - language affiliation (i.e. most recent colonial ties) and religion. This approach allows us to avoid omitted variables not captured by the broad culture variable, especially in the case of Islamic countries, where countries like Indonesia (the largest Muslim country) differs substantially in language affiliation, as well as in culture and traditions from other Muslim countries such as Saudi Arabia.

Also, this model is modified to estimate the impact of countries with Muslim dominance, and then, by disaggregating the Muslim sample to assess the Sunni effect on trade by controlling for political freedom and some pertinent regional trading arrangements (RTA). These RTA encompass the Gulf Cooperation Council (GCC), Association of Southeast Asian Nations (ASEAN), and European Union (EU), and are selected based on the proximity feature of the gravity theory (i.e. major blocs within a geographic proximity of the majority of Islamic countries).

Subsequently, the modified model becomes:

$\log M i j=\alpha+\beta \log (G D P i * G D P j)+\eta \log \left(P C I i^{*} P C I j\right)+\theta \log (D I S T i j)+\mu(B O R D E R i j)+\psi($ LANGUAGEij $)$ $+\varphi($ MUSLIMij $)+\pi($ SUNNIij $)+\Sigma^{n}{ }_{1} \chi($ RTAij $)+\delta(P O L$ FREEij $)$

$\log T i j=\alpha+\beta \log (G D P i * G D P j)+\eta \log \left(P C I{ }^{*} P C I j\right)+\theta \log ($ DISTij $)+\mu(B O R D E R i j)+\phi(O I L i)+\lambda($ OILj $)$ $+\psi($ LANGUAGEij $)+\varphi($ MUSLIMij $)+\pi($ SUNNIij $)+\Sigma^{n}{ }_{1} \chi($ RTAij $)+\delta(P O L$ FREEij $)$,

where Mij and Tij are imports and total trade, respectively, between countries $i$ and $j ; \alpha, \beta, \eta, \theta, \mu, \phi, \lambda, \psi, \varphi, \pi, \chi$ and $\delta$ are the estimated coefficients of the constant term, size of economy, per capita income, distance, border, reporter and partner oil-exporting countries, language affiliation, Muslim countries, Sunni countries, regional trade arrangements (GCC, ASEAN, EU), and political freedom, respectively.

It is expected that the value of trade positively correlates with the size of economy and per capita income, and negatively with distance. The dummy variable "border" is assigned ' 1 ' in case both countries share common borders, while the "oil" dummy variables take the value of ' 1 ' if reporter (or partner) country is an oil-exporter. It is hypothesized that Muslim countries trade less than others, and that Sunni, in particular, trade more than their Shiite counterparts. As a result the modified model incorporates the Muslim dummy variable (Muslim $=1$; otherwise $=0$ ); thus expecting a negative link. And then, the extended model disaggregates the Muslim sample to measure the Sun- 
ni impact on trade (Sunni $=1$; otherwise $=0$ ). This latter incorporation of the Sunni sect variable depicts that the trading partners (exporter and importer) are either both Sunni or at least one Sunni and the other partner is not Shiite. Similarly, the same sect dummy variable takes the value of zero when both trading partners are Shiite or at least one is Shiite and the other is not Sunni. This Sunni dummy variable is the main explanatory variable of this study and is expected to be positively related with trade.

Moreover, regional trade arrangements are all expected to be positive, though not necessarily significant for the GCC, which although may be trade creating in a Middle Eastern framework but not as much as in a global one (Mehanna and Hassan, forthcoming). Because regimes in many Islamic countries may cast some doubt on the level of democracy and social/civil liberties and their role in affecting trade policies, therefore the ordinal variable "political freedom" is incorporated to describe the level of political freedom across countries. The ordinal variable "political freedom" is measured on a scale of $1=$ free, $2=$ partly free, and $3=$ not free, which is measured through an array of surveys representing the level of freedom in a country, and is published by the Freedom House. Freer nations are expected to experience more trade, hence a positive relationship with trade.

All trade and GDP values are in real and constant US\$ and are averaged from 1996 through 1999. Data are taken from the IMF Direction of Trade Statistics, the World Bank World Development Indicators and governments' web sites.

\section{Empirical Analysis}

Descriptive statistics (Table 1) show a large dispersion in trade figures ranging from $\$ 1.5$ billion up to $\$ 12$ billion. In addition, imports figures could run from zero up to $\$ 11$ billion; thus, suggesting that some countries do not import from each other at all, while in other cases their product trade figures could amount to billions of dollars. Data also point out that some income disparities exist in the sample, though not too wide-reflected by standard deviation of 2 and a mean of 17-and various sizes of economies are also included. It also seems natural that oilexporting countries comprise a significant share of the sample under study, which is mainly due to the existing cluster of some Muslim countries rich in Oil as reflected by an approximate mean of 0.39 (expected value of both means).

The cross-sectional nature of this study allows us to use the ordinary least squares (OLS) estimation technique, where we can benefit from the rich amount of information, but which it also raises suspicion of some heteroskedasticity in the error term. In fact, the heteroskedasticity in the error term is detected and addressed by using the White's procedure (1980), which gives robust-heteroskedasticity estimates for the variance-covariance matrix of the estimated regression coefficients.

Table 2 reports the regression estimates of the gravity model when testing for religion. Results show that Muslim countries trade significantly less than Christian, Buddhists, Hindus, and other counterparts. In other words, a country with a Muslim majority population tend to have an average of 0.7 percent in imports and 0.93 percent in trade less than the model predicts, ceteris paribus. The coefficient estimates of the size of the economy, the income per capita, the distance, and the border variables have their expected signs and are highly significant, which is consistent with the gravity theory.

Table 3 represents the disaggregated Muslim sample, and reports the regression results when testing for the Islamic sect on trade and imports. Findings show that countries with Sunni majority tend to trade significantly more than their Shiite counterparts. Empirically, a Sunni country, import 0.47 percent and trade 0.39 percent more than the Shiite countries, holding every else constant. Also, when introducing the Sunni variable, the other estimated coefficients kept their signs - an implication of the relevance and non-redundancy of this "sect" variable.

The modified gravity model tests for the relevant RTA by adding the three blocs: GCC, ASEAN, and EU to the system equation (see Table 4). Findings reveal that Muslim countries are still highly significant and negatively related to trade and imports. Conversely, Sunni countries are highly significant and positively associated with trade and imports. The new incorporated set of RTA dummy variables show that GCC has some positive tendency for 
trade creation (significant in the case of import but not trade), EU is statistically insignificant, and ASEAN shows a highly significant trade creation, ceteris paribus. Other variables kept their expected signs.

The final extended model (see Table 5) incorporates political freedom (another control variable), and reports that an increase in political freedom tends to positively impact trade but not imports. However, the basic determinants of the gravity model along with oil, RTA, and political freedom variables are included to adequately control for this study explanatory variables: Muslim and Sunni. Consequently, Muslim and Sunni are reported to have respectively the expected negative and positive links with trade (and imports).

\section{Conclusions, Policy Implications, and Future Research}

This paper investigates the impact of Islam and Islamic sects on bilateral trade activities across countries for the average period 1996-99. A modified version of the gravity model is adopted. Unlike previous studies that examined the effects of religion, culture, or language on trade, this study disaggregate the religion variable into a sectarian variable to estimate the effect of Islamic sects on trade. Additionally, it augments the gravity model so to control for RTA, oil-exporting countries, political freedom, and another aspect of culture-language affiliation.

Results indicate that, on average, Muslim countries trade less between each other than their Christian, Buddhist or other counterparts. More importantly, after disaggregating the Muslim variable into Sunni and Shi'a sects, findings reveal that Sunni countries trade significantly more than their Shiite counterparts.

Even after controlling for countries that are members of regional trading arrangements (thus, having lower trade barriers) and political freedom (that could be a relevant factor associated with trade in Islamic countries), still the Muslim and Sunni variables kept their significant signs, which may imply for more robust results.

The aforementioned findings suggest that Muslim and especially Shiite countries should introduce more trade policy oriented reforms that encompass the introduction of political reforms, the liberalization and the openness of their economies. In addition, Muslim Shiite countries should give more priority to their trade policies, and should embark on regional and international-scale strategies through, either forming, widening or deepening their RTA and/or building new alliances with other larger economies such as the United States, EU and other RTA.

Perhaps the GCC econometric result, which points out to some "tendency" in trade creation (though not always statistically significant) could encourage some Muslim countries to join, expand, and deepen this trade bloc so it may become more trade creating. Nevertheless, the structural and natural trade impediments of many Muslim countries, such as the similarity of factor endowments and the lack of product complementarity, especially in the Middle East, may require broader and more effective measures such as the diversification of their economies, which may play an essential role in fostering their intra-trade activities. This latter note could be an interesting topic for future research.

In a nutshell, although this study indicates that Sunni do trade more than Shiite, still Muslim countries, in general, lag far behind in their trade activities compared with the rest of the world. Therefore, the aforementioned economic and political policy aspects should be addressed by Shiite countries as well as by all Muslim countries, in order to collaborate together, and create some new efficient resources that could enable them to bargain on the international arena. 
Table 1. Descriptive Statistics

\begin{tabular}{lllll} 
Variable & Minimum & Maximum & Mean & Standard Deviation \\
\hline Log Imports ij & 0.01 & 11.19 & 5.44 & 2.51 \\
Log Trade ij & 1.56 & 12.17 & 6.46 & 2.22 \\
Log GDP ij & 3.11 & 17.34 & 9.8 & 2.74 \\
Log PCI ij & 11.67 & 20.68 & 17.29 & 1.99 \\
Log Distance & 3.97 & 11.09 & 7.82 & 0.9 \\
Border & 0 & 1 & 0.05 & 0.21 \\
Oil ij & 0 & 1 & 0.38 & 0.48 \\
Language ij & 0 & 1 & 0.63 & 0.42 \\
Muslim ij & 0 & 1 & 0.54 & 0.49 \\
Sunni ij & 0 & 1 & 0.59 & 0.49 \\
GCC & 0 & 1 & 0.02 & 0.15 \\
EU & 0 & 1 & 0.04 & 0.19 \\
ASEAN & 0 & 1 & 0.02 & 0.13 \\
Political Free ij & 1 & 3 & 2.03 & 0.87 \\
\hline
\end{tabular}

Valid sample size $(\mathrm{N}=481)$

Table 2. Gravity Model Regression Results, testing for Culture (language) and Religion (Islam)

\begin{tabular}{|c|c|c|c|c|}
\hline \multirow{2}{*}{$\begin{array}{l}\text { Dependent } \\
\text { Variable }\end{array}$} & \multicolumn{2}{|c|}{ Log Imports } & \multicolumn{2}{|c|}{ Log Trade } \\
\hline & Coefficient & $t$-statistics & Coefficient & $t$-statistics \\
\hline Constant & $2.179 * *$ & 2.149 & $2.832 * * *$ & 3.741 \\
\hline Log GDP ij & $.676^{* * *}$ & 18.825 & $.612 * * *$ & 22.749 \\
\hline Log PCI ij & $.112 * * *$ & 3.155 & $.124 * * *$ & 4.671 \\
\hline Log DIST & $-.612 * * *$ & -7.467 & $-.514 * * *$ & -8.473 \\
\hline BORDER & $.786 * *$ & 2.450 & $.747 * * *$ & 3.151 \\
\hline Oil ij & -- & -- & $.475 * * *$ & 3.342 \\
\hline Language ij & $.84 * * *$ & 6.660 & $.9 * * *$ & 6.910 \\
\hline Muslim ij & $-.84 * * *$ & -4.872 & $-.832 * * *$ & -5.167 \\
\hline Adjusted $\mathrm{R}^{2}$ & \multicolumn{2}{|c|}{0.62} & \multicolumn{2}{|c|}{0.68} \\
\hline F-value & \multicolumn{2}{|c|}{286.745} & \multicolumn{2}{|c|}{240.599} \\
\hline$p$-value of $F$ & \multicolumn{2}{|c|}{.000} & \multicolumn{2}{|c|}{.000} \\
\hline DW & \multicolumn{2}{|c|}{1.956} & \multicolumn{2}{|c|}{1.796} \\
\hline$\underline{\mathrm{N}}$ & \multicolumn{2}{|c|}{484} & \multicolumn{2}{|c|}{482} \\
\hline
\end{tabular}

Note: $\mathrm{p}$-values $*<.1 ; * *<.05 ; * * *<.01$

Table 3. Gravity Model Regression Results, testing for Islamic Sects (Sunni)

\begin{tabular}{|c|c|c|c|c|}
\hline \multirow{2}{*}{$\begin{array}{l}\text { Dependent } \\
\text { Variable }\end{array}$} & \multicolumn{2}{|c|}{ Log Imports } & \multicolumn{2}{|c|}{ Log Trade } \\
\hline & Coefficient & $t$-statistics & Coefficient & $t$-statistics \\
\hline $\begin{array}{l}\text { Constant } \\
\text {. }\end{array}$ & $2.504 * *$ & 2.486 & $3.125 * * *$ & 4.145 \\
\hline $\log$ GDP ij & $.672 * * *$ & 18.847 & $.610 * * *$ & 22.861 \\
\hline $\log$ PCI ij & $.118 * * *$ & 3.342 & $.129 * * *$ & 4.921 \\
\hline Log DIST & $-.670 * * *$ & -8.026 & $-.561 * * *$ & -9.109 \\
\hline BORDER & $.719 * *$ & 2.256 & $.695 * * *$ & 2.958 \\
\hline Oil ij & -- & -- & $.412 * * *$ & 2.901 \\
\hline Language ij & $.78 * * *$ & 6.41 & $.87 * * *$ & 6.84 \\
\hline Muslim ij & $-1.120 * * *$ & -5.766 & $-1.024 * * *$ & -6.052 \\
\hline Sunni ij & $.469 * * *$ & 3.036 & $.389 * * *$ & 3.371 \\
\hline Adjusted $\mathrm{R}^{2}$ & \multicolumn{2}{|c|}{.61} & \multicolumn{2}{|c|}{0.72} \\
\hline F-value & \multicolumn{2}{|c|}{179.753} & \multicolumn{2}{|c|}{219.825} \\
\hline$p$-value of $F$ & \multicolumn{2}{|c|}{.000} & \multicolumn{2}{|c|}{.000} \\
\hline DW & \multicolumn{2}{|c|}{1.979} & \multicolumn{2}{|c|}{1.783} \\
\hline $\mathrm{N}$ & \multicolumn{2}{|c|}{483} & \multicolumn{2}{|c|}{481} \\
\hline
\end{tabular}

Note: $\mathrm{p}$-values $*<.1 ; * *<.05 ; * * *<.01$ 
Table 4. Gravity Model Regression Results, testing for Religion (Islam), Islamic Sect (Sunni), and RTA

\begin{tabular}{lllll} 
Dependent & \multicolumn{2}{c}{ Log Imports } & \multicolumn{2}{c}{ Log Trade } \\
Variable & Coefficient & $t$-statistics & Coefficient & t-statistics \\
\hline Constant & $2.204 * *$ & 2.101 & $2.576^{* * *}$ & 3.304 \\
Log GDPij & $.681 * * *$ & 18.981 & $.610^{* * *}$ & 22.861 \\
Log PClij & $.115 * * *$ & 3.166 & $.137 * * *$ & 5.146 \\
Log DIST & $-.638 * * *$ & -6.471 & $-.52 * * *$ & -7.153 \\
BORDER & $.607 *$ & 1.888 & $.65 * * *$ & 2.771 \\
Oil ij & -- & -- & $.391 * * *$ & 2.781 \\
Language ij & $.74 * * *$ & 6.67 & $.86 * * *$ & 6.83 \\
Muslim ij & $-1.087 * * *$ & -5.48 & $-.912 * * *$ & -5.358 \\
Sunni ij & $.451 * * *$ & 2.931 & $.347 * * *$ & 3.045 \\
GCC & $.738 *$ & 1.72 & .181 & .567 \\
EU & -.231 & -.596 & -.044 & -.157 \\
ASEAN & $1.408 * * *$ & 3.052 & $1.513 * * *$ & 4.462 \\
Adjusted R & & 0.616 & & 0.704 \\
F-value & & 129.929 & & 172.837 \\
p-value of F & & 0.000 & & 0.000 \\
DW & & 1.994 & & 1.832 \\
N & & 483 & & 481 \\
\hline
\end{tabular}

Note: $\mathrm{p}$-values $*<.1 ; * *<.05 ; * * *<.01$

Table 5. Gravity Model Regression Results, testing for Religion (Islam), Islamic Sect (Sunni), RTA, and Political Freedom

\begin{tabular}{|c|c|c|c|c|}
\hline \multirow{2}{*}{$\begin{array}{l}\text { Dependent } \\
\text { Variable }\end{array}$} & \multicolumn{2}{|c|}{ Log Imports } & \multicolumn{2}{|c|}{ Log Trade } \\
\hline & Coefficient & $t$-statistics & Coefficient & $t$-statistics \\
\hline Constant & 1.537 & 1.341 & $1.746^{* *}$ & 1.988 \\
\hline Log GDP ij & $.69^{* * *}$ & 18.976 & $.618 * * *$ & 22.982 \\
\hline Log PCI ij & $.135 * * *$ & 3.475 & $.162 * * *$ & 5.538 \\
\hline Log DIST & $-.626 * * *$ & -6.344 & $-.50 * * *$ & -6.841 \\
\hline BORDER & $.575 *$ & 1.785 & $.622 * * *$ & 2.656 \\
\hline Oil ij & -- & -- & $.294 * *$ & 1.984 \\
\hline Language ij & $.71 * * *$ & 5.401 & $.73 * * *$ & 5.460 \\
\hline Muslim ij & $-1.229 * * *$ & -5.549 & $-1.001 * * *$ & -5.712 \\
\hline Sunni & $.509 * * *$ & 3.204 & $.418 * * *$ & 3.517 \\
\hline GCC & .658 & 1.522 & .1430 & .448 \\
\hline $\mathrm{EU}$ & -.205 & -.529 & -.003 & -.012 \\
\hline ASEAN & $1.454 * * *$ & 3.147 & $1.587 * * *$ & 4.671 \\
\hline Political Freedom & .066 & 1.437 & $.073 * *$ & 2.029 \\
\hline Adjusted $\mathrm{R}^{2}$ & \multicolumn{2}{|c|}{0.652} & \multicolumn{2}{|c|}{0.726} \\
\hline F-value & \multicolumn{2}{|c|}{118.572} & \multicolumn{2}{|c|}{160.92} \\
\hline $\mathrm{p}$-value of $\mathrm{F}$ & \multicolumn{2}{|c|}{0.000} & \multicolumn{2}{|c|}{0.000} \\
\hline DW & \multicolumn{2}{|c|}{1.981} & \multicolumn{2}{|c|}{1.815} \\
\hline $\mathrm{N}$ & \multicolumn{2}{|c|}{483} & \multicolumn{2}{|c|}{481} \\
\hline
\end{tabular}

Note: $\mathrm{p}$-values $*<.1 ; * *<.05 ; * * *<.01$

\section{References}

1. Al-Atrash, Hassan and Tarik Yousef, 2000, "Intra-Arab Trade: Is It Too Low?,” IMF Working Paper 00/10 (Washington: International Monetary Fund).

2. Beckerman, William, 1956, "Distance and the Pattern of Inter-European Trade," Review of Economics and Statistics, vol. 38 pp. 31-40.

3. Bergstrand, Jeffrey, 1985, "The Gravity Equation in International Trade: Some Microeconomic Foundations and Empirical Evidence," Review of Economics and Statistics, vol. 67 (August) pp. 474-81.

4. Choudhury, Masudul Alam, 1997, "Money in Islam: A Study in Islamic Political Economy," International 
Studies in Money and Banking, vol. 3 (xvii) p. 313.

5. Cindoruk, Sadi, 1992, "Economic Cooperation Among OIC Countries and Islamic Common Market," Journal of Economic Cooperation Among Islamic Countries, vol. 13 (12) pp. 1-18.

6. Ensminger, Jean, 1997, "Transaction Costs and Islam: Explaining Conversion in Africa," Journal of Institutional and Theoretical Economics, vol. 153 (1) pp. 4-29.

7. Ghazali, Aidit bin Haji, 1994, "Consumer Credit from the Islamic Viewpoint," Journal of Consumer Policy, vol. 17 (4) pp. 443-458.

8. Hassan, M. Kabir, 2000, "Success and Failure of Various Groups of OIC Countries." Monograph, Islamic Economics Research Bureau, Dhaka, Bangladesh.

9. Huntington, Samuel P., 1993, "The Clash of Civilization," Foreign Affairs, vol. 72 pp. 22-49.

10. Lazear, Edward P., 1999, "Culture and Language," Journal of Political Economy, vol. 107 (6) pp. 95-126.

11. Matyas, Laszlo, 1997, "Proper Econometric specification of the Gravity Model," The World Economy, vol. 20 (3) pp. 363-369.

12. Mehanna, Rock-Antoine and M. Kabir Hassan, 2002, On Openness, Integration, Stability and Economic Growth (Bangladesh Institute of Islamic Thought: Dhaka, Bangladesh).

13. Mehanna, Rock-Antoine and Kabir Hassan, forthcoming, "Is the Gulf Cooperation Council a Successful Trading Bloc? A Middle Eastern Framework," Middle East Business and Economic Review.

14. Srivastava, Rajendra K. and Robert T. Green, 1986, "Determinants of Bilateral Trade Flows," Journal of Business, vol. 59 (4) pp. 623-640.

15. Valibeigi, Mehrdad, 1993, "Islamic Economics and Economic Policy Formation in Post-Revolutionary Iran: A Critique," Journal of Economic Issues, vol. 27 (September) pp. 793-812.

16. White, Halbert, 1980, "A Heteroskedasticity-Consistent Covariance Matrix Estimator and a Direct Test for Heteroskedasticity,” Econometrica, vol. 48, pp. 817-838. 